Article

\title{
Shear Behavior of a Reinforced Concrete Frame Retrofitted with a Hinged Steel Damping System
}

\author{
Hyun-Do Yun ${ }^{1} \mathbb{D}$, Sun-Woong Kim ${ }^{2}$, Wan-Shin Park ${ }^{3} \mathbb{1}$ and Sun-Woo Kim ${ }^{3, * \mathbb{C}}$ \\ 1 Department of Architectural Engineering, Chungnam National University, Daejeon 34134, Korea; \\ wiseroad@cnu.ac.kr \\ 2 AMS Engineering Co., Ltd., Daejeon 34077, Korea; kswoong1@naver.com \\ 3 Department of Construction Engineering Education, Chungnam National University, Daejeon 34134, Korea; \\ salshin@cnu.ac.kr \\ * Correspondence: sw.kim@cnu.ac.kr; Tel.: +82-42-821-8568
}

Received: 28 October 2020; Accepted: 10 December 2020; Published: 11 December 2020

check for updates

\begin{abstract}
The purpose of this study was to experimentally evaluate the effect of a hinged steel damping system on the shear behavior of a nonductile reinforced concrete frame with an opening. For the experimental test, a total of three full-scale reinforced concrete frame specimens were planned, based on the "no retrofitting" (NR) specimens with non-seismic details. The main research questions were whether the hinged steel damping system is reinforced and whether torsion springs are installed in the hinged steel damping system. From the results of the experiment, the hinged steel damping system (DR specimen) was found to be effective in seismic retrofitting, while isolating the opening of the reinforced concrete (RC) frame, and the torsion spring installed at the hinged connection (DSR specimen) was evaluated to be effective in controlling the amount of deformation of the upper and lower dampers. The strength, stiffness, and energy dissipation capacity of the DSR specimen were slightly improved compared to the DR specimen, and it was confirmed that stress redistribution was induced by the rotational stiffness of the torsion spring installed in the hinge connection between the upper and lower frames.
\end{abstract}

Keywords: shear behavior; nonductile reinforced concrete frame; hinged steel damping system; seismic retrofitting; stress redistribution

\section{Introduction}

The number of structures has increased with industrial development worldwide, therefore there are many vulnerable structures. However, it is more economical to improve the performance of the structure through reinforcement than to demolish such a damaged structure. As a method for improving the performance of these structures, the seismic retrofitting of structures has attracted the attention of many researchers, and different methods have been developed for the seismic retrofitting of structures. For the local strengthening of structural elements, various jacketing methods such as a reinforced concrete (RC) jacket [1,2], fiber-reinforced concrete (FRC) jacket [3,4], fiber reinforced plastic (FRP) [5] and steel plate jacket [6] have been proposed. Additionally, steel braces and infill walls have been widely employed for the seismic strengthening of vulnerable structures [7-12]. In addition to the aforementioned structural strengthening methods, various energy dissipating devices, such as dampers, first introduced by Kelly et al. [13], have been invented to improve the seismic performance of structures. Among the dampers, metallic yielding dampers are classified as passive control systems with base isolators, friction dampers, viscous and viscoelastic dampers, tuned mass and liquid dampers [14,15]. The main goal of passive control systems, such as metal yield dampers, is to dissipate the input energy by inelastic deformation, so that the energy acting on the structure during an earthquake is dissipated 
by the hysteresis behavior of these elements. Thus, it reduces the contribution of primary structural elements and limits the degree of damage to the structure. These metal dampers generally have a short element length. The simplest metallic damper is a single steel plate, generally welded to the structure, indicated in the literature as a shear panel damper (SPD) [16,17].

Therefore, in order to improve the shear performance of a frame, a metal damper is generally installed under the upper beam of the frame. However, because the length of the damper is short, the brace or wall must be extended upward from the upper or lower beam of the column. This installation method lacks space for the installation of openings such as windows in the frame where the damper is installed. Therefore, it cannot be applied to frames that require opening installations such as windows or doors, if necessary.

In this study, a hinged steel damping system with energy absorbing elements installed at the top and bottom of the opening was developed as a permanent retrofitting method for nonductile frames. The hinged steel damping system proposed in this study was installed on the upper/lower beams of the frame using anchors. All system elements were hinged to isolate the central frame for the installation of openings from external energy. Steel dampers were installed as an energy dissipating device between the horizontal members at the top and bottom of the opening, so that the seismic performance could be expressed when seismic force is applied. In addition, a torsion spring was installed inside the hinge between system elements to induce rotational resistance between system members, so that it can effectively resist lateral forces together with the upper/lower steel dampers. The developed system secures the strength required for seismic retrofitting of structures with non-seismic details, and at the same time prevents the decrease in durability of newly built seismic elements, and facilitates the safe evacuation of the occupants of the building. Therefore, the effect of the hinged steel damping system on the shear behavior of RC frame was experimentally evaluated.

\section{Experimental Program}

\subsection{Test Specimens}

In this study, the effect of the hinged steel damping system on the shear behavior of reinforced concrete frames with non-seismic details was experimentally evaluated.

Figure 1 shows the details of test specimens. A total of three specimens were planned, based on the no retrofitting (NR) specimens with non-seismic details by referring to one of the drawings of a school building with non-seismic details. In the case of low-rise structures such as schools, a column-sway (soft-story) failure mechanism appears on the ground floor when a lateral load such as an earthquake is applied to the structure. In addition, the amount of reinforcement used in the school buildings with non-seismic details targeted in this study is insufficient compared to the current required seismic details. Therefore, the upper and lower beams were designed to have high stiffness so that failure was concentrated to the column in order to implement a column-sway (soft-story) failure mechanism. The dimensions of the beams were determined taking into account the size of the equipment used in the experiment.

The main variables were whether the hinged steel damping system was reinforced and whether a torsion spring was installed in the hinged steel damping system, as listed in Table 1. Full-scale specimens were fabricated in order to consider the size effect of the actual seismic reinforcement details. In this study, torsion springs (SS 316) were installed in the system in order to induce elastic force to help the damper respond to earthquake loads and to facilitate restoration after the deformation of the seismic retrofit system. The body width of the torsion spring that can be used in the system is $24 \mathrm{~mm}$. Under the condition that the inner diameter of the torsion spring is the same, the smaller the number of coils, the larger the wire diameter, the higher the torsional moment, and the allowable angle corresponding to the acceptable bending stress decreases. Therefore, torsion springs with various wire diameters were tested, and as a result of the experiment, the torsion spring with a $6 \mathrm{~mm}$ wire diameter showing the highest rotational stiffness was selected and installed in the system. The rotational stiffness 
of the torsion spring was $34.4 \mathrm{kN} \cdot \mathrm{m} / \mathrm{rad}$. The acceptable bending stress of the spring calculated by the equation proposed by Shigley et al. [18] using the details of the torsion spring (316 SS) used in this study was $644 \mathrm{MPa}$, and the corresponding allowable angle was about 28 degree (0.489 rad). In general, the allowable angle within the elastic range of the torsion spring is relatively large, while the rotation angle of the steel damper at fracture is around 5 degrees. Therefore, in order to increase the contribution of the torsion spring to the lateral load resistance of the damper and the stability when the load is being removed by applying the load in the opposite direction, it is effective to use a spring with a larger torsional moment if possible. Details of the torsion spring used in the hinged steel damping system of the DSR specimen are shown in Figure 2.

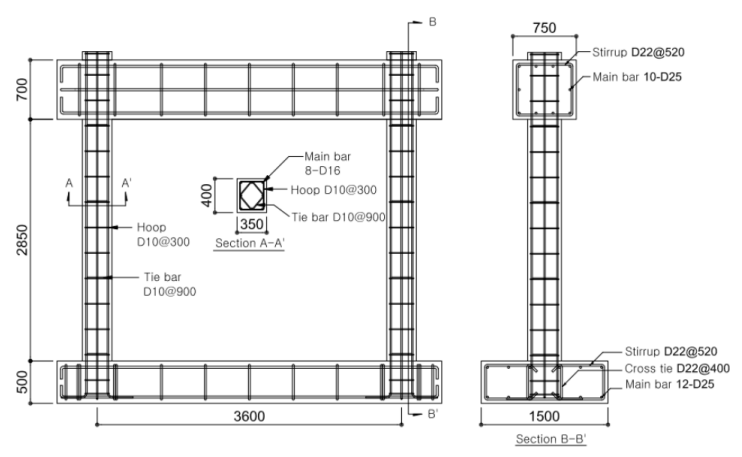

(a)

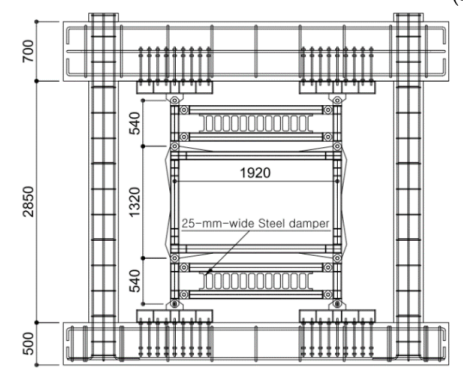

(b)

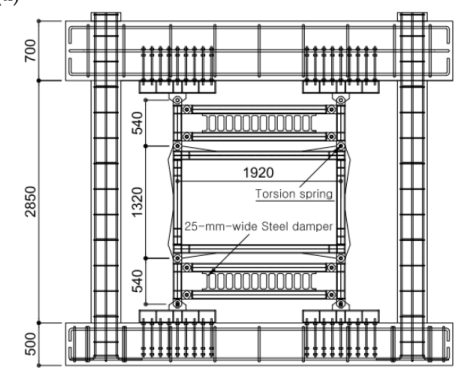

(c)

Figure 1. Details of test specimens (unit: mm): (a) no retrofitting (NR); (b) damper retrofitting (DR); (c) damper and spring retrofitting (DSR).

Table 1. List of test specimens.

\begin{tabular}{|c|c|c|c|c|c|c|c|c|c|c|}
\hline \multirow{3}{*}{ Specimen * } & \multicolumn{6}{|c|}{ Column } & \multicolumn{4}{|c|}{ Hinged Steel Damping System } \\
\hline & \multirow[b]{2}{*}{$\begin{array}{l}\text { Section } \\
(\mathrm{mm})\end{array}$} & \multirow[b]{2}{*}{$\begin{array}{l}\text { Length } \\
\text { (mm) }\end{array}$} & \multirow[b]{2}{*}{$\begin{array}{l}\text { Spacing } \\
(\mathrm{mm})\end{array}$} & \multicolumn{3}{|c|}{ Steel Reinforcement } & \multicolumn{3}{|c|}{ Steel Damper } & \multirow[b]{2}{*}{$\begin{array}{c}\text { Spring at } \\
\text { Hinge }\end{array}$} \\
\hline & & & & Main & Hoop & Tie & $\begin{array}{c}\text { Thickness } \\
(\mathrm{mm})\end{array}$ & $\begin{array}{l}\text { Width } \\
(\mathrm{mm})\end{array}$ & $\begin{array}{l}\text { Spacing } \\
(\mathrm{mm})\end{array}$ & \\
\hline NR & & & & & & & N/A & $\mathrm{N} / \mathrm{A}$ & N/A & N/A \\
\hline $\begin{array}{c}\text { DR } \\
\text { DSR }\end{array}$ & $350 \times 400$ & 2850 & 3600 & 8-D16 & D10@300 & D10@900 & 6 & 25 & 100 & $\begin{array}{l}X \\
O\end{array}$ \\
\hline
\end{tabular}

* NR: specimen with No Retrofitting; DR: specimen with Damper Retrofitting; DSR: specimen with Damper and Spring in Retrofitting.

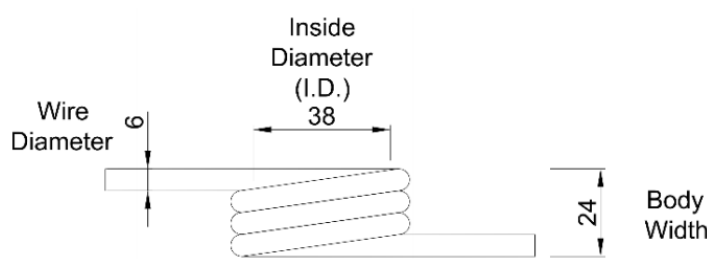

Figure 2. Details of torsion spring (unit: $\mathrm{mm}$ ).

In this study, a hinged steel damping system was applied for seismic retrofitting of a reinforced concrete frame with non-seismic details, and the reinforcement effect of each detail of the seismic 
reinforcement system was experimentally evaluated. As shown in Figure 3, the test specimens were prepared in the following order: fabrication of the base for the reinforced concrete frame Figure 3a, the assembly of reinforcement on the upper part of the specimen including columns Figure $3 \mathrm{~b}$, fabrication of the reinforced concrete frame, and installation of the hinged steel damping system Figure 3c. A total of 72 anchor bolts (SS400) were used to install the steel damping system to the RC frame in order to ensure that the anchor sufficiently resisted the shearing force. The anchor bolts were embedded with a sufficient anchorage length $(400 \mathrm{~mm})$ in the top and bottom horizontal beams in advance when fabricating the specimen. Details of the anchoring bolts are shown in Figure 4.

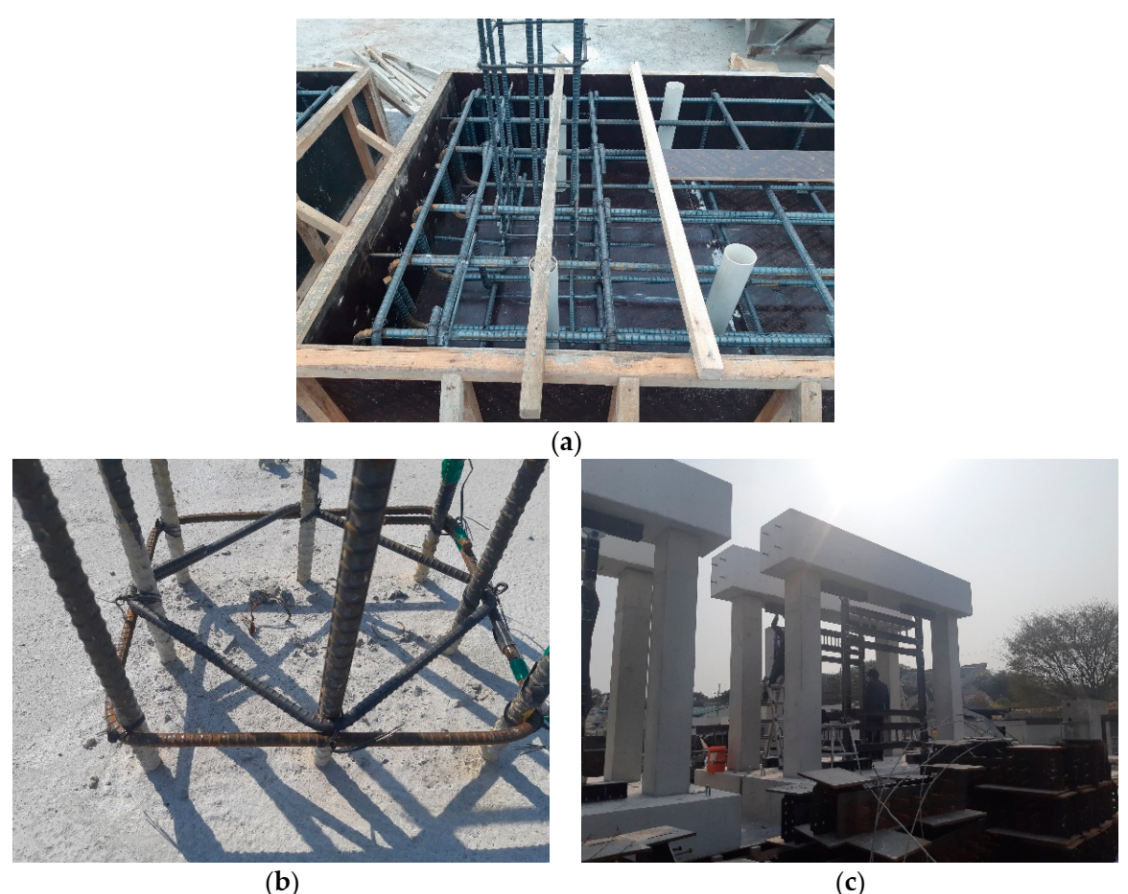

Figure 3. Test specimen fabricating process: (a) Form and reinforcement work for base; (b) Column reinforcement assembly; (c) Completion of the reinforced concrete (RC) frame retrofitted with hinged steel damping system installation.

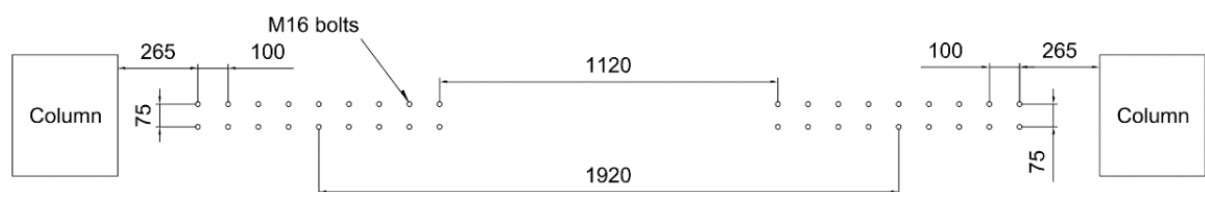

Figure 4. Details of anchoring bolts on the top and bottom horizontal beams (plan view).

\subsection{Materials}

In this study, $18 \mathrm{MPa}$-strength concrete and SD400 grade steel reinforcement were used to fabricate reinforced concrete frames with non-seismic details. For the hinged steel damping system installed inside the frame, an SS400 class H-beam $(\mathrm{H}-100 \times 100 \times 6 \times 8)$ and steel plate $(6 \mathrm{~T})$ were used. In accordance with KS F 2403 [19], three cylindrical specimens ( $D=100 \mathrm{~mm}$ ) were cast in steel molds and kept in a moist room at $23{ }^{\circ} \mathrm{C}$ and $95 \%$ relative humidity for $24 \mathrm{~h}$ until demolding. The specimens were then placed in water at $23^{\circ} \mathrm{C}$ for a total curing period of 28 days. At 28 days, compressive tests were conducted in accordance with KS F 2405 [20]. For steel materials, three tensile test specimens for each steel material were prepared in accordance with KS B 0801 [21], and tensile tests were conducted in accordance with KS B 0802 [22]. The strength characteristics of the concrete and the mechanical properties of the steel are shown in Tables 2 and 3, respectively. 
Table 2. Strength properties of concrete.

\begin{tabular}{cccc}
\hline Type & $\left.f_{c} \mathbf{( M P a}\right)$ & $\varepsilon_{c}\left(\times 10^{-6}\right)$ & $E_{c}(\mathbf{G P a})$ \\
\hline Concrete & 25.8 & 2923 & 16.2 \\
\hline
\end{tabular}

Table 3. Mechanical properties of steel rebar and plate.

\begin{tabular}{cccc}
\hline & Type & $f_{\boldsymbol{y}}$ (MPa) & $f_{\boldsymbol{u}}$ (MPa) \\
\hline \multirow{2}{*}{ Rebar } & D10 & 471 & 591 \\
& D16 & 455 & 573 \\
Plate & Slit damper (6T) & 405 & 468 \\
& H-beam (8T) & 406 & 448 \\
\hline
\end{tabular}

\subsection{Test Method}

Figure 5 shows the test setup for the specimen. The lower part of the specimen was fixed to the reaction floor, and a base fixing system was additionally installed to prevent slip when applying a lateral load. As for the axial force applied to the specimen, $10 \%$ of the column axial compressive strength was designed to act as a sustained vertical load using two oil jacks and a loading frame fixed to the reaction force floor. Horizontal load was applied to the reinforced concrete frame specimen using a $2000 \mathrm{kN}$ capacity actuator, and the load was gradually increased by the displacement control method as shown in Figure 6. In addition, the decrease in stiffness due to the repeated loading was evaluated by applying the load three times in repeated cycles during the same displacement control. The displacement and strain of the reinforced concrete frame and seismic reinforcement system were measured during the test using linear variable differential transformers (LVDTs) and strain gages. Figure 7 shows the layout of the LVDTs and the strain gage installed on the RC frame and the hinged steel damping system, and all data were recorded during the experiment. As shown in the figure, the displacement of the top horizontal beam (D2) was measured using LVDT2, and the slip of the bottom horizontal beam (D1) was measured using LVDT1. Using these two displacements, the net horizontal displacement (D2-D1) was obtained. Strain gages were also attached to the steel damper and opening frame.

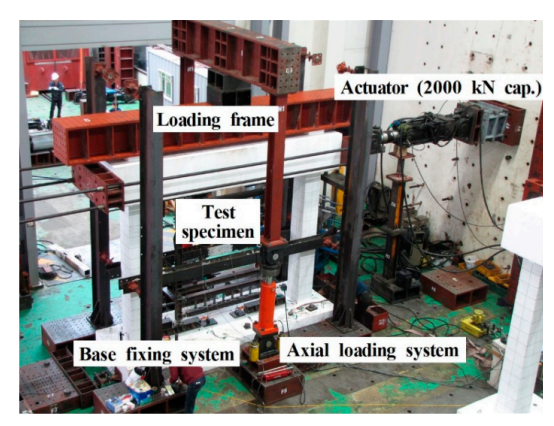

Figure 5. Test setup.

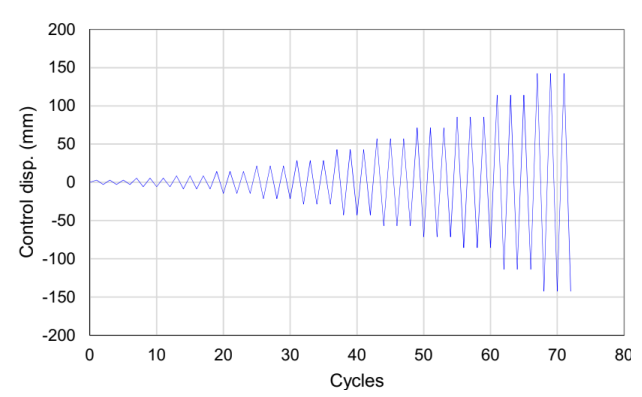

Figure 6. Loading history. 


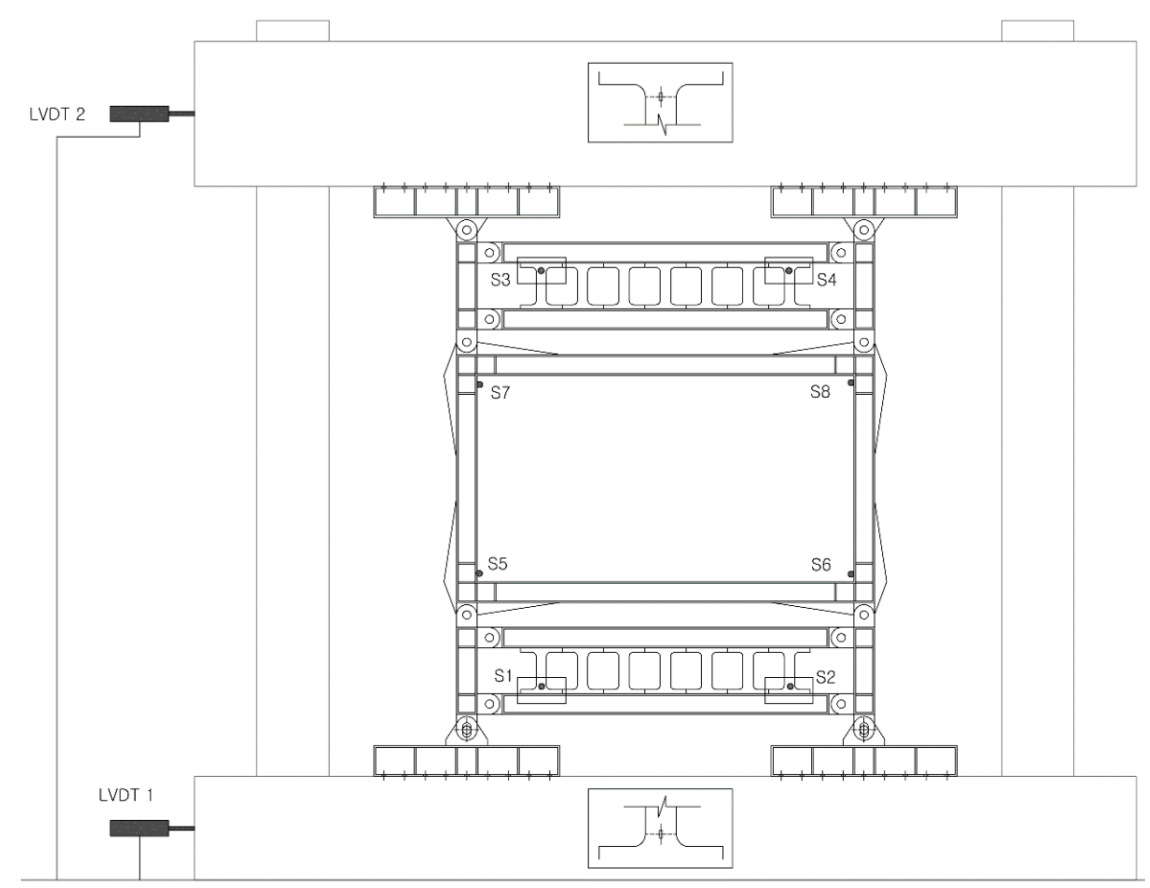

Figure 7. Layout of instruments (linear variable differential transformers (LVDTs) and strain gauges).

\section{Experimental Results and Discussion}

\subsection{Cracking and Failure Modes}

Figure 8 shows the final failure mode of the test specimen. In the case of the NR specimen with non-seismic details, initial cracks occurred at the top and bottom of the column at a drift ratio of $0.15 \%$ (displacement $4.3 \mathrm{~mm}$ ). Thereafter, as the drift ratio increased, cracks began to develop toward the center of the column as well as in the upper and lower columns. At a drift ratio of $1.00 \%(28.5 \mathrm{~mm})$, cracks developed up to one third of the height of the upper and lower part of columns, and the number of generated cracks also increased rapidly. At a drift ratio of $2.50 \%(71.3 \mathrm{~mm})$, crushing began to occur at the top and bottom of the column. At a drift ratio of $3.00 \%(85.5 \mathrm{~mm})$, the NR specimen failed as the strength was rapidly lost due to crushing and an increased crack width at the top and bottom of the column.

In the case of the DR specimen with a width of $25 \mathrm{~mm}$ of steel dampers installed at the top and bottom of the hinged steel damping system, the failure mode of the reinforced concrete frame was similar the that of the NR specimen. As the drift ratio increased, the deformation of the opening frame and the upper and lower steel dampers gradually increased. At a drift ratio of $2.50 \%(71.3 \mathrm{~mm})$, the steel dampers installed at the top and bottom of the hinged steel damping system yielded, resulting in significant deformation. At a drift ratio of $4.00 \%(114.0 \mathrm{~mm})$ the plastic deformation of the steel damper subsequently increased, resulting in a decrease in strength, and the damper gradually fractured.

The fracture pattern of the DSR specimen with an additional torsion spring installed at the hinged connection between the upper and lower frames of the DR specimen was similar to that of the NR specimen, which was a non-seismic detailed reinforced concrete frame. As the drift ratio increased, the deformation of the opening frame and the upper and lower steel dampers gradually increased. At a drift ratio of $2.50 \%(71.3 \mathrm{~mm})$, the steel dampers installed at the top and bottom of the system yielded, resulting in significant deformation. However, due to the sharing of the load capacity of the torsion spring installed in the hinged connection, the gradual decrease in the load capacity that occurred in the DR specimen was not observed. The DSR specimen failed while showing a plastic deformation of the steel damper and a concomitant decrease in proof stress when the drift ratio was controlled at $4.00 \%$ (114.0 mm). 
In the case of the DR and DSR specimens in which the steel dampers showed plastic deformation, the upper and lower dampers showed similar deformation at the beginning, but the plastic deformation occurred intensively in the area where the yield load was first reached. Theoretically, it is desirable to design the deformation of the upper and lower dampers to be the same, so that it simultaneously reaches yield and undergoes plastic deformation. However, in this study, it was judged that the deformation occurs predominantly in the part which yields first, either the upper or lower part, due to errors in the fabrication and construction process of the actual seismic retrofitting system. As shown in the experimental results for the DSR specimen in this study, the unbalanced deformation of the upper/lower dampers could be slightly compensated for through the application of a torsion spring. However, in order to maximize the performance effect of the seismic retrofitting system, it is necessary to develop a connection detail that allows the upper and lower parts to be simultaneously deformed.

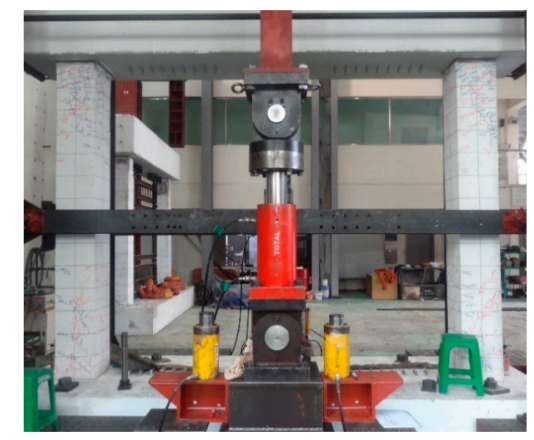

(a)

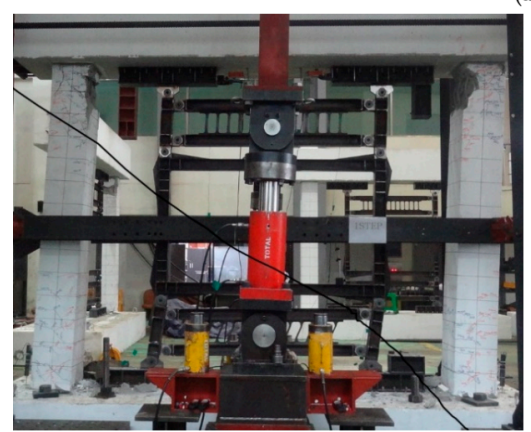

(b)

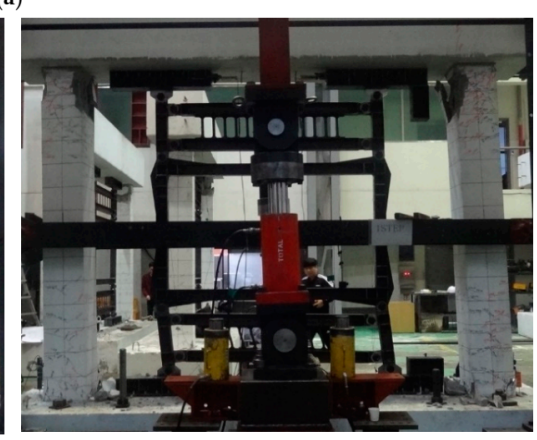

(c)

Figure 8. Final failure modes of the test specimens: (a) NR; (b) DR; (c) DSR.

\subsection{Load-Displacement Relationships}

The load-displacement relationship curves of the specimens are shown in Figure 9. In the case of the NR specimen with non-seismic details, the longitudinal reinforcement of the column yielded at $223.0 \mathrm{kN}$. The displacement at this time was $42.2 \mathrm{~mm}$ and the yield stiffness was $5.3 \mathrm{kN} / \mathrm{mm}$. The maximum shear strength of the specimen was $232.0 \mathrm{kN}$, and the displacement at this time was $63.6 \mathrm{~mm}$ and the maximum stiffness was $3.7 \mathrm{kN} / \mathrm{mm}$.

In case of the DR specimen with a width of $25 \mathrm{~mm}$ steel dampers installed on the top and bottom of the hinged steel damping system, the longitudinal reinforcement of the column yielded at $275.1 \mathrm{kN}$. The displacement at this time was $45.0 \mathrm{~mm}$, which was similar to that of the NR specimen with non-seismic details, and the yield stiffness was $6.1 \mathrm{kN} / \mathrm{mm}$, a slight increase due to the hinged steel damping system. The maximum shear strength of the specimen was $286.9 \mathrm{kN}$, which was $23.7 \%$ higher than that of the NR specimen with non-seismic details, and the displacement at this time was $68.1 \mathrm{~mm}$ and the maximum stiffness was $4.2 \mathrm{kN} / \mathrm{mm}$.

In the case of the DSR specimen with an additional torsion spring installed at the hinged connection between the upper and lower frames of the DR specimen, the longitudinal reinforcement of the column yielded at $258.2 \mathrm{kN}$. The displacement at this time was $37.1 \mathrm{~mm}$, and the yield of the 
column reinforcement occurred earlier than that of the NR specimen with non-seismic details, and the yield stiffness increased slightly to $7.0 \mathrm{kN} / \mathrm{mm}$. The maximum shear strength of the specimen was $286.0 \mathrm{kN}$, which was $23.3 \%$ higher than that of the NR specimen with non-seismic details, and the displacement at this time was $66.4 \mathrm{~mm}$ and the maximum stiffness was $4.3 \mathrm{kN} / \mathrm{mm}$.

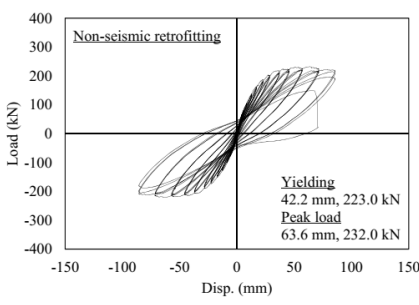

(a)

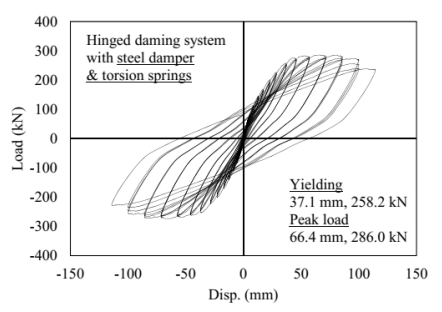

(c)

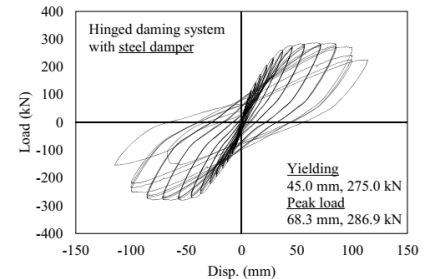

(b)

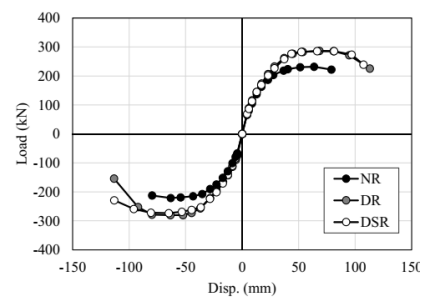

(d)

Figure 9. Load-displacement curves for test specimens: (a) NR; (b) DR; (c) DSR; (d) envelope curves.

Figure $9 \mathrm{~d}$ shows a comparison of the envelope at each cycle in the load-displacement relationship curve of the specimen. As shown in the figure, the maximum shear strength was improved by $23 \sim 30 \%$ due to the hinged steel damping system. DR specimens with steel dampers installed at the top/bottom of the hinged steel damping system showed a rapid decrease in strength as the drift ratio increased after the maximum strength. However, the DSR specimen displayed a tendency of increased ductility without decreased strength after the maximum load due to the installed torsion spring, representing the most desirable retrofitting performance. Additionally, because the torsion spring used within the scope of this study was within the elastic range even after the steel damper was fractured, it is judged that the torsional spring is effective in controlling the amount of deformation of the upper and lower dampers. The experimental results are summarized in Table 4.

Table 4. Test results.

\begin{tabular}{|c|c|c|c|c|c|c|c|c|c|}
\hline \multirow[b]{2}{*}{ Specimen } & \multicolumn{3}{|c|}{ Yielding } & \multicolumn{3}{|c|}{ Peak Load } & \multirow{2}{*}{$\begin{array}{l}\text { Load Component of } \\
\text { Steel Damper (kN) }\end{array}$} & \multirow{2}{*}{$\begin{array}{l}\text { Predicted Strength of } \\
\text { Steel Damper }(\mathrm{kN})\end{array}$} & \multirow{2}{*}{$\begin{array}{c}\text { Dissipated } \\
\text { Energy } \\
(\mathrm{kN} \cdot \mathrm{m})\end{array}$} \\
\hline & $\begin{array}{l}\text { Load } \\
\text { (kN) }\end{array}$ & $\begin{array}{l}\text { Disp. } \\
(\mathrm{mm})\end{array}$ & $\begin{array}{l}\text { Stiffness } \\
\text { (kN/mm) }\end{array}$ & $\begin{array}{l}\text { Load } \\
(\mathrm{kN})\end{array}$ & $\begin{array}{l}\text { Disp. } \\
\text { (mm) }\end{array}$ & $\begin{array}{l}\text { Stiffness } \\
(\mathrm{kN} / \mathrm{mm})\end{array}$ & & & \\
\hline NR & 223.0 & 42.2 & 5.3 & 232.0 & 63.6 & 3.7 & N/A & N/A & 144.9 \\
\hline DR & 275.0 & 45.0 & 6.1 & 286.9 & 68.3 & 4.2 & 54.9 & 68.3 & 310.3 \\
\hline DSR & 258.2 & 37.1 & 7.0 & 286.0 & 66.4 & 4.3 & 54.0 & 68.3 & 320.4 \\
\hline
\end{tabular}

The strength of the steel damper in Table 4 was calculated by Equations (1) and (2) suggested by Benavent Climent et al. [23].

$$
\begin{aligned}
& Q_{y}=\min \left\{n \frac{\sigma_{y} t B^{2}}{2 H^{\prime}}, n \frac{2 \sigma_{y} t B}{3 \sqrt{3}}\right\} \\
& Q_{B}=\min \left\{n \frac{\sigma_{B} t B^{2}}{2 H^{\prime}}, n \frac{2 \sigma_{B} t B}{3 \sqrt{3}}\right\}
\end{aligned}
$$

where, $n$ is the number of struts ( $n=13$ in this study), $Q_{y}$ is the minimum value of the total plastic moment and shear force calculated using the yield strength of the steel $\left(\sigma_{y}\right), Q_{B}$ is the minimum value of the total plastic moment and shear force calculated using the maximum strength of the steel $\left(\sigma_{B}\right)$, 
$t$ is the strut thickness, $B$ is the strut width, and $H$ is the equivalent height ( $H=140 \mathrm{~mm}$ in this study) calculated as given in Figure 10.

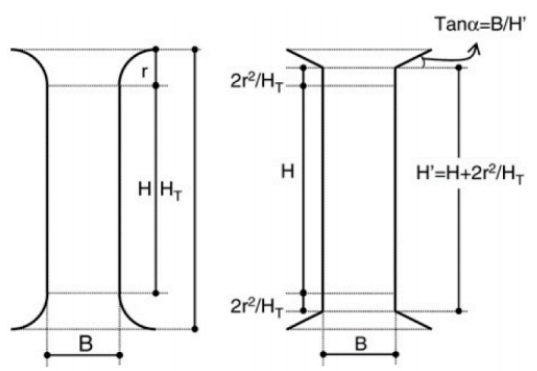

Figure 10. Idealization of slit damper [23].

\subsection{Stiffness Degradation Characteristic}

Figure 11 compares the stiffness of the specimen normalized to the stiffness of the first cycle. As shown in the figure, the DR and DSR specimens retrofitted with the hinged steel damping system showed gentle stiffness degradation compared to the NR specimens with non-seismic details. In addition, the DSR specimen with the torsion spring added to the hinged steel damping system applied to the DR specimen exhibited a stable stiffness drop until the final failure.

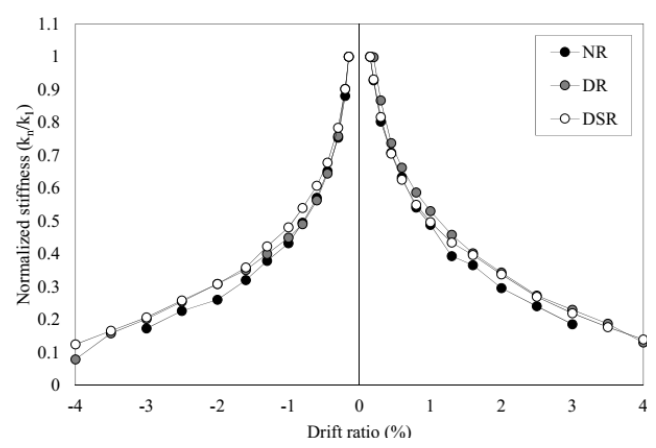

Figure 11. Comparison of stiffness degradation characteristics.

\subsection{Energy Dissipation Capacity}

Figure 12 shows a comparison of the cumulative energy dissipation capacity of the test specimen. As shown in the figure, the cumulative energy dissipation capacity of the NR specimen with non-seismic details was $144.9 \mathrm{kN} \cdot \mathrm{m}$. The cumulative energy dissipation capacity of the DR specimen with steel dampers installed at the top and bottom of the hinged steel damping system was $310.3 \mathrm{kN} \cdot \mathrm{m}$, showing a $114 \%$ increase in energy dissipation capacity compared to the NR specimen. In addition, the cumulative energy dissipation capacity of the DSR specimen with the torsion spring added to the hinged steel damping system applied to the DR specimen was $320.4 \mathrm{kN} \cdot \mathrm{m}$, which was $121 \%$ higher than that of the NR specimen. It showed the best energy dissipation ability, for example by increasing energy dissipation capability.

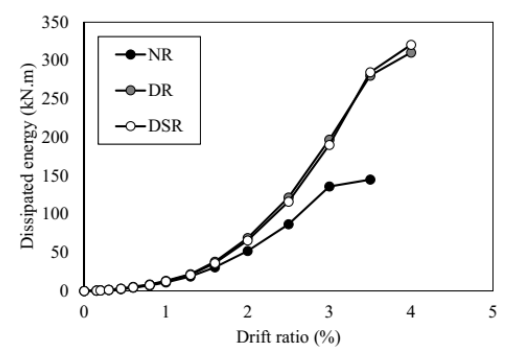

Figure 12. Energy dissipation capacities of test specimens. 


\subsection{Steel Strain Characteristics}

Figure 13 shows the comparison of strain gage values attached to dampers in the DR and DSR specimens. As shown in Figure 13a,b, in the case of the DR specimen, the strain value of the steel damper showed a large difference between the upper and lower parts, whereas in the case of the DSR specimen shown in Figure 13c, d, the strain values of the upper and lower steel dampers were similar.

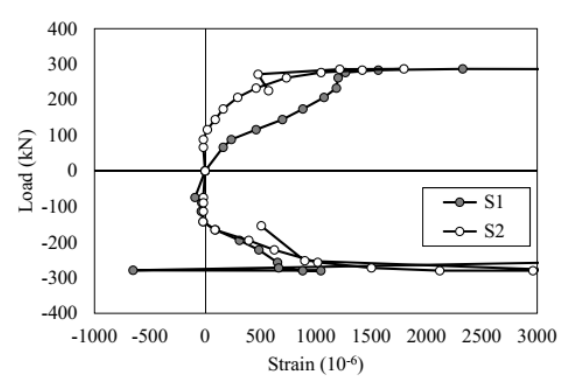

(a)

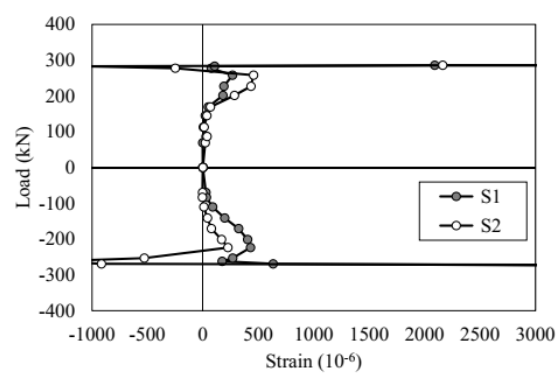

(c)

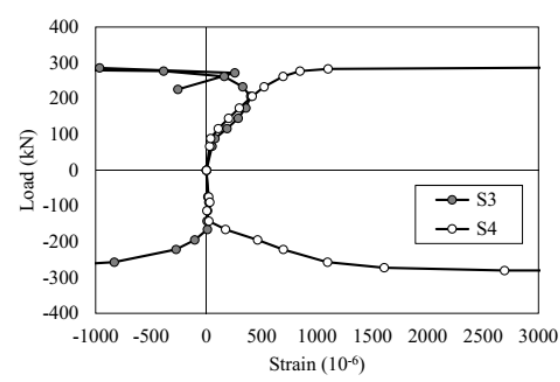

(b)

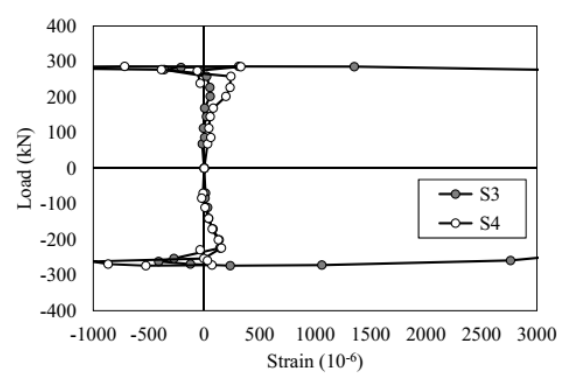

(d)

Figure 13. Strain characteristics of dampers: (a) lower damper of the DR specimen; (b) upper damper of the DR specimen; (c) lower damper of the DSR specimen; (d) upper damper of the DSR specimen.

Figure 14 shows the comparison of values of strain gages attached to the inside of the opening in DR and DSR specimens. As shown in the figure, in the case of the DSR specimen, the strain values of the opening were lower than those of the DR specimen. More balanced strain characteristics were observed between the left and right openings in the DSR specimen, compared to the DR specimen. This was due to the torsion spring installed in the DSR specimen, and it can be inferred that stress redistribution occurred such that the upper/lower steel dampers show a balanced strain characteristic. When the maximum displacement is reached and the force is applied in the opposite direction again, it is determined that a balanced stress distribution has occurred toward the upper and lower damper elements due to the characteristics of the spring to be restored within the elastic range.

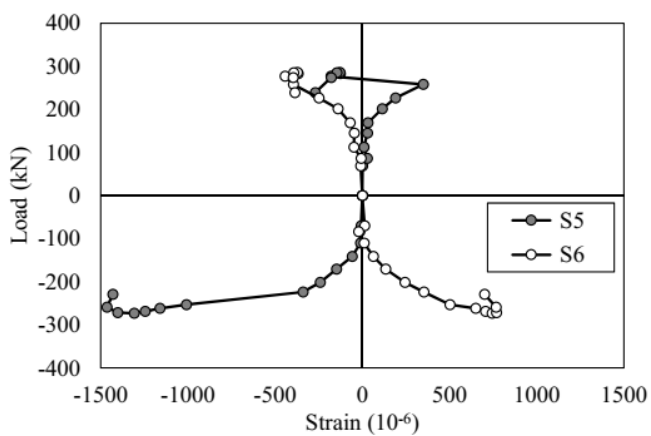

(a)

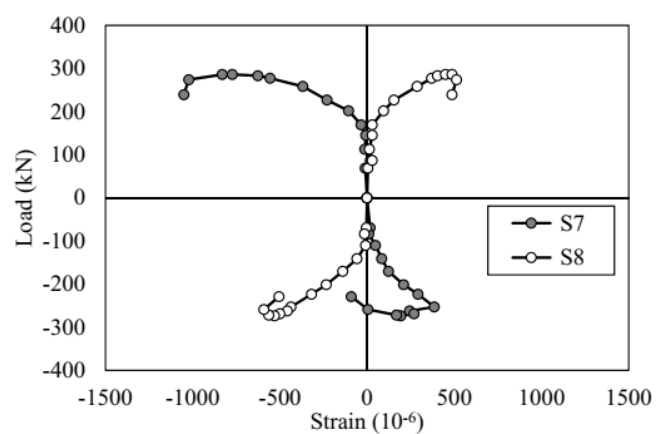

(b)

Figure 14. Cont. 


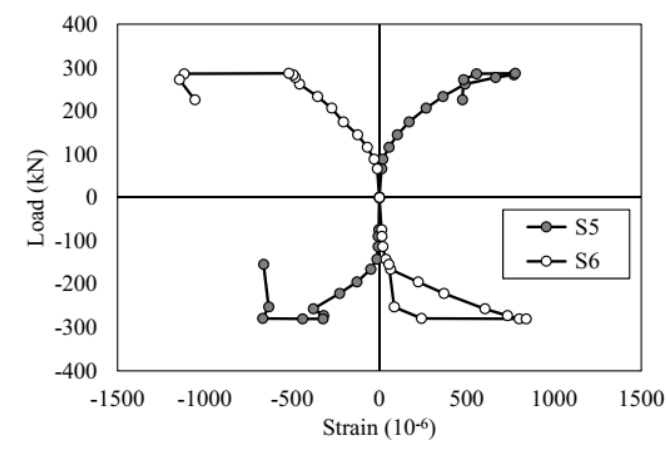

(c)

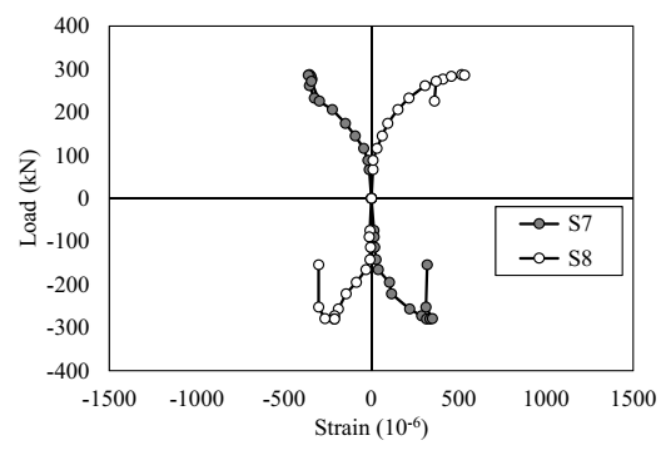

(d)

Figure 14. Strain characteristics of openings: (a) lower left and right part of the opening of the DR specimen; (b) upper left and right part of the opening of the DR specimen; (c) lower left and right part of the opening of the DSR specimen; (d) upper left and right part of the opening of the DSR specimen.

\section{Conclusions}

In this study, the developed hinged steel damping system was applied to a nonductile reinforced concrete frame to experimentally evaluate the seismic retrofitting effect. $\mathrm{RC}$ frames for testing were produced by referring to one of the drawings of a school building with non-seismic details. In order to implement a column-sway failure mechanism of low-rise structure such as schools, the upper and lower beams of the test specimen were designed to have high stiffness so that failure was concentrated to the column. When retrofitting the structure, it is necessary to install windows in the opening and to construct a filling material using insulation in the space inside the frame excluding the opening. Additionally, because the behavioral characteristics of the RC frame change as such construction is carried out, there is a limit to fully describe the seismic retrofitting effect of the proposed system. Conclusions drawn within the scope of this study are summarized as follows.

(1) The DR specimen with the hinged steel damping system showed a gradual decrease in strength and finally failed.

(2) The strength, stiffness, and energy dissipation capacity of the DSR specimen were slightly improved compared to the DR specimen, and it was confirmed that stress redistribution was induced by the rotational stiffness of the torsion spring installed in the hinge connection between the upper and lower frames.

(3) Between the upper and lower dampers, plastic deformation occurred intensively in the damper that reached the yield load first as the displacement increased. Therefore, further detailed development and experimental verification are required in future studies so that the damper, which is a seismic resistance element, can act symmetrically at the top and bottom.

(4) In actual structures, the clearance dimensions between columns or between the upper beam and the floor are not precise due to construction errors. The system developed in this study took this into account, and an extra length was provided for the hinge connection. However, it may be one of the causes of the asymmetric deformation of the upper/lower dampers in the experimental results. In addition, when the proposed system was applied to a nonductile RC frame, the seismic performance of the structure must be accurately identified, and this must be considered in the design of the system's H-beam and steel damper.

(5) In this study, anchors were pre-installed in the top and bottom horizontal beams to prevent performance degradation factors such as construction errors. The characteristics of anchoring connections are vital for the performance of the whole retrofitted system. Even if the calculated fixing length is applied, there is a possibility that the anchoring ability cannot be exhibited depending on the construction situation. Therefore, it is recommended to use a sufficiently larger amount than the calculated amount of anchoring bolts in consideration of performance degradation factors such as construction errors. In addition, it is essential to prevent damage to 
the reinforcing bar by detecting the location of the reinforcing bar inside the existing reinforced concrete member before anchoring.

(6) The system proposed in this study has upper/lower dampers to dissipate energy from earthquakes, therefore it is possible to reduce the stress transmitted to the primary members of the existing $\mathrm{RC}$ structure. As a result of the experiment, it is judged that the proposed system prevents the transfer of stress to the opening because small deformations occur in the opening even though the steel dampers are in a plastic deformation state. Additionally, if the upper and lower dampers are damaged by an earthquake, only the dampers need to be replaced, so the proposed system can be used for permanent seismic retrofit of existing structures.

(7) In order to apply the details or construction methods proposed through this study, it is necessary to evaluate the performance of the existing structure, and furthermore to carry out performance evaluations and study the design formula of the reinforcement system to calculate the appropriate reinforcement amount.

Author Contributions: Conceptualization, H.-D.Y. and S.-W.K. (Sun-Woo Kim); methodology, S.-W.K. (Sun-Woong Kim) and S.-W.K. (Sun-Woo Kim); validation, H.-D.Y. and W.-S.P.; writing-original draft, S.-W.K. (Sun-Woo Kim); writing-review and editing, H.-D.Y. and W.-S.P. All authors have read and agreed to the published version of the manuscript.

Funding: This work was supported by a research fund of Chungnam National University (2019-0622-01).

Conflicts of Interest: The authors declare no conflict of interest.

\section{References}

1. Zhao, Y.; Zhang, D.; Shen, S.; Ueda, T. Axial loading capacity of concrete-jacketed RC columns with pre-and post-corrosion damage. Struct. Concr. 2016, 17, 355-364. [CrossRef]

2. Anvari, A.; Ghalehnovi, M.; de Brito, J.; Karimipour, A. Improved bending behaviour of steel-fibre-reinforced recycled aggregate concrete beams with a concrete jacket. Mag. Concr. Res. 2020,1-19. [CrossRef]

3. Gholampour, A.; Hassanli, R.; Mills, J.E.; Vincent, T.; Kunieda, M. Experimental investigation of the performance of concrete columns strengthened with fiber reinforced concrete jacket. Constr. Build. Mater. 2019, 194, 51-61. [CrossRef]

4. Deng, M.; Zhang, Y. Cyclic loading tests of RC columns strengthened with high ductile fiber reinforced concrete jacket. Constr. Build. Mater. 2017, 153, 986-995. [CrossRef]

5. Mohammed, A.A.; Manalo, A.C.; Ferdous, W.; Zhuge, Y.; Vijay, P.V.; Pettigrew, J. Experimental and numerical evaluations on the behaviour of structures repaired using prefabricated FRP composites jacket. Eng. Struct. 2020, 210, 110358. [CrossRef]

6. He, A.; Cai, J.; Chen, Q.J.; Liu, X.; Xu, J. Behaviour of steel-jacket retrofitted RC columns with preload effects. Thin-Walled Struct. 2016, 109, 25-39. [CrossRef]

7. Badoux, M.; Jirsa, J.O. Steel bracing of RC frames for seismic retrofitting. J. Struct. Eng. 1990, 116, 55-74. [CrossRef]

8. Roudsari, M.T.; Entezari, A.; Hadidi, M.; Gandomian, O. Experimental assessment of retrofitted RC frames with different steel braces. Structures 2017, 11, 206-217.

9. Rahimi, A.; Maheri, M.R. The effects of steel X-brace retrofitting of RC frames on the seismic performance of frames and their elements. Eng. Struct. 2020, 206, 110149. [CrossRef]

10. Baghi, H.; Oliveira, A.; Valença, J.; Cavaco, E.; Neves, L.; Júlio, E. Behavior of reinforced concrete frame with masonry infill wall subjected to vertical load. Eng. Struct. 2018, 171, 476-487. [CrossRef]

11. Shan, S.; Li, S.; Xu, S.; Xie, L. Experimental study on the progressive collapse performance of RC frames with infill walls. Eng. Struct. 2016, 111, 80-92. [CrossRef]

12. Murty, C.V.R.; Jain, S.K. Beneficial influence of masonry infill walls on seismic performance of RC frame buildings. In Proceedings of the 12th world conference on earthquake engineering, Auckland, New Zealand, 30 January-4 February 2000.

13. Kelly, J.M.; Skinner, R.I.; Heine, A.J. Mechanisms of energy absorption in special devices for use in earthquake resistant structures. Bull. N. Z. Soc. Earthq. Eng. 1972, 5, 63-87. [CrossRef] 
14. Symans, M.D.; Charney, F.A.; Whittaker, A.S.; Constantinou, M.C.; Kircher, C.A.; Johnson, M.W.; McNamara, R.J. Energy dissipation systems for seismic applications: Current practice and recent developments. J. Struct. Eng. 2008, 134, 3-21. [CrossRef]

15. Parulekar, Y.M.; Reddy, G.R. Passive response control systems for seismic response reduction: A state-of-the-art review. Int. J. Struct. Stab. Dyn. 2009, 9, 151-177. [CrossRef]

16. Choi, J.; Abebe, D.Y. Hysteresis characteristics of shear panel damper using SLY120. APCBEE Procedia 2014, 9, 370-375. [CrossRef]

17. Liu, Y.; Aoki, T.; Shimoda, M. Distribution measurement of a shear panel damper developed for bridge structure. J. Struct. 2013, 2013, 1-11. [CrossRef]

18. Shigley, J.E.; Mischke, C.R.; Budynas, R.G. Mechanical Engineering Design, 7th ed.; McGraw-Hill: New York, NY, USA, 2004.

19. Korean Standards Association. KS F 2403. Standard Test Method for Making and Curing Concrete Specimens; Korean Standards Association: Seoul, Korea, 2014.

20. Korean Standards Association. KS F 2405. Standard Test Method for Compressive Strength of Concrete; Korean Standards Association: Seoul, Korea, 2017.

21. Korean Standards Association. KS B 0801. Test pieces for Tensile Test for Metallic Materials; Korean Standards Association: Seoul, Korea, 2017.

22. Korean Standards Association. KS B 0802. Method of Tensile Test for Metallic Materials; Korean Standards Association: Seoul, Korea, 2013.

23. Climent, A.B.; Oh, S.; Akiyama, H. Ultimate energy absorption capacity of slit-type steel plates subjected to shear deformations. J. Struct. Constr. Eng. 1998, 63, 139-147.

Publisher's Note: MDPI stays neutral with regard to jurisdictional claims in published maps and institutional affiliations. 